\title{
Daniel J. Siegel, The Developing Mind: How Relationships and the Brain Interact to Shape Who We Are, Guilford Press, New York-London 2012, pp. 506
}

The interdisciplinary approach in science over the past few decades has been gaining more and more support in the world. It turns out that research teams with specialists in many fields are often able to cope better with the challenges of our times than those that derive their knowledge from only one field. One of the most prominent examples is the project named cognitive science, which purpose is the synthesis of knowledge about the mind and the study of the human cognitive apparatus (Duch, 1998). Using two methods: convergence (combining knowledge from many fields, including, among others, neurobiology, psychology, philosophy, linguistics, artificial intelligence and anthropology) and constraint of interpretations (obtaining one theory explaining a given phenomenon regarding convergence), cognitive science has become fruitful mind-explaining approach (Ochsner \& Kosslyn, 2013).

The problem associated with interdisciplinarity may be the difficulty in finding a common ground for the phenomena under consideration. For example, a common definition of mind that would satisfy all disciplines included in cognitive science is still a challenge. Siegel's project, known as Interpersonal Neurobiology (IPNB), which is itself very similar to a cognitive science project, offers such a common framework for many disciplines by introducing its own definition of mind. According to Siegel, one of the main aspects of what is and how does the mind work can be understood as an "embodied and relational process that regulates the flow of energy and information” (p. 2). Although the introduction

1 Department of Cognitive Science and Epistemology, Institute of Philosophy, Faculty of Humanities, Nicolaus Copernicus University in Toruń, Poland, E-MAIL: wojciech.r.sak@gmail. com. 
of such a cohesive definition could be problematic for the framework of cognitive science itself in its present form (Siegel's definition would rather be treated by cognitive science as an operational definition or a useful heuristic or even only just another point of view on what the mind is), due to the adopted by Siegel objectives (achieving mental health, shortly speaking) this definition of mind seems sufficient, which will become more visible in next sections.

Daniel J. Siegel is a clinical professor of psychiatry at the University of California in Los Angeles School of Medicine. He started working on the IPNB project in the 1990s, resulting in a previously mentioned definition of mind coined in agreement with approximately 40 scientists from various fields. Although this definition has a universal dimension, its usefulness should be considered first of all due to how much it allows a better understanding of how to achieve a healthy mind. Most of Siegel's book publications focus on mental health: working with children [so called parenting books, for example, Brainstorm: The Power and Purpose of the Teenage Brain (Tarcher/Penguin, 2014); The Whole-Brain Child: 12 Revolutionary Strategies to Nurture Your Child's Developing Mind (Random House, 2011); No-Drama Discipline: The Whole-Brain Way to Calm the Chaos and Nurture Your Child's Developing Mind (Bantam, 2014)], psychotherapy (The Mindful Therapist: A Clinician's Guide to Mindsight and Neural Integration (Norton, 2010)), and self-development with use of mindfulness practice [Mindsight: The New Science of Personal Transformation (Bantam, 2010); The Mindful Brain: Reflection and Attunement in the Cultivation of Well-Being (Norton, 2007)]. So, considering Siegel's background and his main works, IPNB project should be seen autonomously from cognitive science, though I will address this relation later.

Certainly the advantage of Siegel's definition of the mind is its intuitiveness (and thus having in mind everything that is clearly visible to us when we use our minds) and coherence with the findings present in cognitive science and its paradigms (Hohol, 2013, pp. 85-152), which it synthesizes. By looking more closely at this definition, we notice this intuitiveness and coherence. Since the mind is, with accordance with this definition, a process, it means that it is something that is subject to constant change (which is consistent with the observed constantly changeable nature of mental states visible using neuroimaging techniques). Then it is an embodied process, not limited only to everything "what the brain is doing", but related to the activity of the whole body (which is consistent with the embodied mind paradigm). Another feature of this process is that it is relational. The mind never works in isolation, but in a continuous relationship, which is internal (relation of some states of mind with the others) and external (mind is always in relation with other minds and/or with the environment). Mind is creating those 
relationships and is also created by them. This is consistent with the embedded (in culture/environment) mind paradigm. Finally, it is not a completely random process, but it has a regulatory function (which in IPNB theory it has mainly a reference to the theory of complex systems). This regulation concerns the flow of information (in simplified terms: the computing paradigm) and energy (general reference to findings in neuroscience). All of these aspects are further developed by the author and examined in order to deliberate on issues of mental health.

The definition of mind given by Siegel is not the only concept in The Developing Mind: How Relationships and the Brain Interact to Shape Who We Are, which is subsumed in such a holistic way. Siegel's publication is filled with interesting ideas that organize and synthesize discoveries found in cognitive science. This happens to be with the idea of how memories are stored, where Siegel defines memory as the change in the probability of activating a particular neural network pattern in the future (pp. 46-51). This definition also synthesizes our knowledge about how memory works and reflects how we study it. The most typical example is the method of priming in cognitive psychology, which is one of the basic research methods in this field. Priming allows to change our neural activity so that certain things are more accessible for us to retrieve from memory, which, as Siegel says, means simply a change in the likelihood of activation of certain neural pattern in the future. The same applies to the process of remembering any information, which is also such a change in probability.

Another concept of Siegel worth mentioning concerns the issue of how to understand the unfolding of the emotional process (pp. 146-185). As Siegel puts it, it always starts with arousal (preliminary assessment by our cognitive system that something in our environment might be relevant for us). Then there is a further evaluation - our cognitive apparatus tries to find out if a given phenomenon is positive or negative for us, whether we would want to come closer to it or leave it, escape from it. Only at the end of the information processing we are able to come to the point where we have such explicit emotions as joy, sadness, etc., and it does not have to always occur.

The way Siegel speaks about all those concepts related to the workings of the mind reveals the most visible difference between cognitive science and IPNB. Siegel's theory concerns all those concepts (mind, memory, emotion, states of mind) in relation to the regulatory role of mind, which he interprets from the perspective of the complex systems theory (pp. 186-218) (the issue of complexity in cognitive science is non-central, being merely one of many issues). Siegel treats this theory as central to understanding what it is and how does the mind work and, above all, how to repair it in the context of well-being. So, different memories could be seen 
as some parts that could be linked and differentiated in complex system, emotions are something that organizes complex states of the mind and so on.

Siegel, trying to get the most complete, holistic picture of how the mind works, opens the way for the reader to understand how the healthy mind works. In his opinion, it is this kind of mind that is integrated and strives for integration (pp. 336-378). The use of the concept of integration can be confusing, because it really is about two things - linking (so, integration) and differentiation, or more precisely connection of differentiated parts. In IPNB, integration makes sense in the context of complex systems. The flow of information and energy in a complex system (which we are as humans) can take place in four ways: in a chaotic, rigid, chaotic and at the same time rigid, and in an integrated manner (p. 148). Translating this into how does the nervous system work, it means, taking as an example a mental disorder, that if the information is processed by a part of the system that works improperly-rigidly (for example, impairment of the brain module of Theory of Mind in autism) and/or chaotically (like loose and excess associations in schizophrenia), then we will have to deal with reduced mental well-being and less optimized life.

According to Siegel, the path to healing is integration (pp. 336-339), which means a process of making neural networks more ductile and changing parts of the network, so that they can become fully functional (which is what differentiation in this approach really means) and combining those parts with other parts to create a functioning whole. To convey the subjective feelings of integration, Siegel uses the acronym FACES (p. 336). The flow of information and energy through the integrated system takes place in a way that leads to harmony and, according to Siegel, is felt as a flow which is "Flexible, Adaptive, Coherent (holding together dynamically over time), Energized, and Stable” (p. 347). Siegel devotes a great deal of space to explain how complex systems work (including terms such as selforganization, maximization of complexity, harmony), discussing in a very subtle way how this translates into our inner experience.

In the epilogue of the book, Siegel lists the nine domains of integration that he has chosen (integration of consciousness, bilateral integration, vertical integration, memory integration, narrative integration, state integration, interpersonal integration, temporal integration, transpiration integration -integration of integration), the ones he believes one should give special attention to when working on oneself. As Siegel points out, "Integration is created in mind, brain, body, and relationships" (p. 336), and working on these domains is particularly recommended. A more detailed discussion of these nine integration domains is contained in his book Mindsight: The New Science of Personal Transformation (Bantam, 2010). 
Siegel's work is a great introduction to the mind, mainly due to the very holistic and synthesizing approach, which has been enriched with complex system theory. In addition, Siegel's approach offers an extraordinary perspective on how to work on the quality of our experience in our lives leading to higher psychological well-being and a more optimal life in harmony with ourselves, others and the world. It also puts forward many proposals that can be of great importance not only for public health, but also for education and the development of science in the field of the mind.

Nevertheless, in the concept of the IPNB, in its present form, one can find many limitations and areas that need to be developed. The first of them is central for Siegel concept of integration, which, as he suggests, is the way of how we should think about how mental health looks like. Although the author devotes a lot space to this issue, the discussion of the concept with such big potential seems to be too cursory. There is no solid analysis of how the IPNB works in a number of mental diseases, how it explains their course and the recovery process. In particular, it would be useful to have such an analysis taking into account schizophrenia, one of the most difficult mental disorders to deal with. The very concept of integration, in my opinion, requires further refinement. One could say, for example, that the part of the concept of integration that concerns linkage should be considered in terms of balance. It is not difficult to imagine that the excess of connections between the various parts can lead to chaos - which is consistent with the IPNB, but such examples should be more clearly marked and analysed in the book that aspires to be the "theory of everything" in the context of a healthy mind. The theory requires more refinement to be more sound.

The author also disproportionately devotes a lot of attention to the phenomenon of attachment - creation of bonds between the child and his caregivers. Compared to such extensive issues as memory or emotions, this disproportion is very visible. This can probably be justified by the education and specialization of the author in this matter. Nevertheless, it is in my opinion a clear omission for such publication in which the author suggests that his approach may be fully applied in psychiatry and may contribute to the reformulation of the bible of psychiatrists - the Diagnostic and Statistical Manual of Mental Disorders (p. 14).

I also have to mention the writing style of the book. As it was mentioned, Siegel introduces new and complex issues very subtly and in - as much as possible - easy way. Unfortunately, the attempt to describe such complicated issues in the possibly accessible way results in redundancy, continuous repetition of many issues discussed above, which then should be blamed not so much on the author as on the editors of the book. 
Despite of all drawbacks, Siegel's book should be recommended to people who want to learn something new about how to care for their mental health and harmonious life, as well as to those who seek inspiration in the field of cognitive science. Taking into account Siegel's background and - related with it - his main objectives about mental health, we can find clear indication for the justification of autonomy of the IPNB project in relation to cognitive science, despite strong similarities. In my opinion, this is the main advantage of Siegel's approach, because the resulting multiplicity of concepts may prove to be actually useful for a cognitive science project. In turn, if Siegel's concept will be developed - I hope that with a greater help of people dealing with cognitive science, complex systems theory, psychology and psychiatry - one can expect to gain a solid theory about achieving mental health, which I warmly wish for Siegel and for all of us.

\section{References}

Duch, W. (1998). Czym jest kognitywistyka? Kognitywistyka i Media w Edukacji, 1 (1), pp. 9-50.

Hohol, M. (2013). Wyjaśnić umysł: struktura teorii neurokognitywnych. Kraków: Copernicus Center Press.

Ochsner, K.N., \& Kosslyn, S. (2013). Introduction to "The Oxford Handbook of Cognitive Neuroscience": Cognitive Neuroscience - Where Are We Now?. Retrieved from: http://www. oxfordhandbooks.com/view/10.1093/oxfordhb/9780199988693.001.0001/oxfordhb9780199988693-e-009 (accessed: 25.03.2018).

Siegel, D.J. (2012). The Developing Mind: How Relationships and the Brain Interact to Shape Who We Are. New York-London: Guilford Press. 